\title{
HeLENo GODOY*
}

\section{RESUMO}

Este ensaio tenta mostrar, através da leitura de alguns poemas e um trecho em prosa de autores diversos (Nicanor Parra, Eve Merriam, Donald Caswell, Freedom Nyamubaya e Lynn Freed), como se constituem as crises através das quais a poesia se transforma e como poetas de diferentes nacionalidades e propósitos aceitam o desafio e tentam superá-las.

Palavras-chave: Poesia e crise poética, desafios Poéticos, Transformações poéticas.

“... acredito que só em situações extremas é que a poesia pode eclodir."

Hilda Hilst

“As aves da noite", Teatro completo (1968)

“... o escritor [...] vê sua obrigação relacionada à verdade do que pode acontecer na vida, e não ao leitor - não ao gosto do leitor, não à felicidade do leitor, nem mesmo à moral do leitor. Flannery O'Connor

"Catholic Novelists and Their Readers", Mystery and Manners: Occasional Prose

"O que é poesia se ela não declara motim?

Se não se livra de tiranos?

O que é poesia se ela não atiça vulcões onde precisamos deles?

E o que é poesia se ela não desloca a coroa

\footnotetext{
* Doutor em Letras pela Universidade de São Paulo (USP), São Paulo, São Paulo, Brasil. Professor titular aposentado da Universidade Federal de Goiás (UFG), Goiânia, Goiás, Brasil. E-mail: hgodoy@brturbo.com.br
} 
Usada pelos poderosos reis deste mundo?"

Nizar Qabbani

"A Very Secret Report from Fist Country", On Entering the Sea: The Erotic and Other Poetry of Nizar Qabbani (1996)

Se me perguntam qual poesia é possível em tempo de crise, respondo achar difícil precisar, pois, para mim, poesia que não reflete uma, ou qualquer, ou todas as crises, não chega a se constituir verdadeiramente como poesia. Lembro aqui versos de um poema de Nicanor Parra, "Cartas del Poeta que Duerme en una Silla", na sua quinta parte, em que o grande poeta chileno diz ser permitido aos jovens poetas fazer/tentar/testar qualquer coisa, pois "em poesia se permite tudo", com somente uma condição, acrescenta o poeta na décima terceira parte do mesmo poema, os jovens poetas devem "superar a página em branco"’2. Essa, para mim, é a única tarefa (ou 'dever', como diz Parra) do poeta e de sua poesia, 'superar (isto é, melhorar) a página em branco'. Em si, isso já é crise mais do que suficiente para um poeta; sem isso, nenhuma poesia está em crise, entra em crise, tenta superar qualquer crise. Mas crio aqui um hiato, para explicar duas ou três coisas a meu respeito, coisas em que acredito, coisas que me revelam, coisas que, de uma forma ou de outra, norteiam meu trabalho como poeta há cinquenta anos.

Se me perguntam sobre o que me motiva a escrever, respondo que escrevo por não saber 'não escrever'. Escrever, para mim, é vital: sem escrever não sou quem quero ser ou quem gostaria de me tornar, se pudesse melhorar quem sou. Embora tente sempre fazer isso, sem nem ao menos saber se sou o que penso ser: Escrevo para ser e estar e me manter - por escrever, sobrevivo. Por isso não acredito em poesia circunstancialmente política, ou pior, partidária, pois se nenhuma linguagem é inocente, qualquer poesia é, de saída, comprometida. Também não acredito em poesia escrita para angariar fama e projeção nunca fui, nem quero ser, atleta da fama, inscrito na maratona da glória. Não é essa a minha "corrida".

Se também me perguntam quais foram ou são os meus modelos de escritores, faço uma distinção e respondo que inúmeros poetas contribuíram, em primeiro lugar, para a minha 'educação'; outros, em segundo lugar, para a minha 'formação' como poeta. Dentre os que 
me educaram, menciono quatro: Manuel Bandeira, o que mais amo e releio, para me acalmar e voltar a acreditar que as coisas valem a pena; Fernando Pessoa, que me ajudou a entender o que é que a poesia pode ser e a diferença entre o 'ser' e 'poder ser' da poesia, e assim me dividir e me multiplicar; Carlos Drummond de Andrade, com quem tenho relação respeitosa de discípulo que admira racionalmente (nunca emocionalmente) o mestre, mas o teme, por ter aprendido com ele a objetividade; e Jorge de Lima, o outro mais amado depois de Bandeira, e com quem aprendi a ter fé intelectual e emocional na poesia, na sua necessidade e na sua eficácia, mesmo quando ninguém pensa nela ou dela fala ou the dá valor.

Em segundo lugar, dentre os poetas que contribuíram para minha 'formação', e foram apenas três, acredito, menciono: João Cabral de Melo Neto, Mário Chamie e, pode ser e talvez seja estranho, a norteamericana Marianne Moore. Com Cabral aprendi a me distanciar do poema e vê-lo com objetividade crítica, a elidir o eu intrusivo e, na maioria das vezes, 'atrapalhante', para deixar apenas a visão clara e precisa das coisas fluindo, da vida acontecendo, aquilo que é. Não é a pretensão de fazer a coisa correta, mas a de procurar estar seguro de que não estou 'encontrando' uma ideia alheia, nem 'obtendo' uma forma semelhante, mas buscando 'atingir' uma forma que seja minha, ou que eu possa dizer que é minha.

Com Chamie aprendi a prática ou práxis da construção do livro, que não pode ser apenas um ajuntamento de poemas escritos ao longo de algum tempo, mas uma forma também ela atingida, um todo estruturado de modo específico, nunca ao acaso. Alguém diria que parece a ideia de Mallarmé do livro como 'a palavra total'. Sim, mas as razões para isso são totalmente diferentes das do poeta francês. Reconheço, evidentemente, que a linguagem de Chamie me influenciou muito, no início de minha trajetória. Isso explica que publiquei meu primeiro livro de poesia, Os veículos, em 1968, e o segundo, fábula fingida, só em 1984 - foram dezesseis anos tentando me libertar da linguagem de Chamie, e creio ter conseguido, embora do resto de sua influência não queira me libertar, nem mesmo, parcialmente, de sua linguagem, já que ela me obriga a estar atento na busca da minha própria.

Por fim, aprendi com Marianne Moore a dicção contida, o distanciamento que Cabral já me havia incutido e ela fez frutificar; 
sobretudo, a aprendizagem do ritmo muito próximo da prosa, embora sem cair nela, e a falar de "jardins imaginários com sapos reais", desde que se entenda ou se considere a poesia como "um lugar para o genuíno". De qualquer forma, com ela também aprendi "o amor da ordem, o ardor, e a simplicidade não indireta".

Se me perguntam, ainda, como definiria meu trabalho de poeta, acho que preferiria responder com um poema da norte-americana Eve Merriam $^{3}$, que apresento aqui, em tradução minha:

"Resposta à Pergunta: 'Como Você se Tornou Poeta?’”

tome a folha de uma árvore

trace sua forma exata

suas bordas externas

e suas linhas internas

memorize o modo como se prende à haste

(e como a haste arqueia a partir do galho)

como em abril ela se expande

como em julho ela se enrijece

em fins de agosto

amasse-a em sua mão

para que você cheire sua tristeza de fim de verão

mastigue seu talo de madeira

ouça seu tagarelar de outono

veja como no ar de novembro ela se pulveriza

no inverno então

quando não há folha que sobre

invente uma. ${ }^{4}$

'Inventar' - essa é a palavra, pois nos ajuda a entender uma verdade (lembremo-nos de Aristóteles ${ }^{5}$ ), a de que todo poeta é/deve 
ser um inventor e um descobridor ("fabulador"), pois tem como parte de sua natureza descobrir novas relações entre coisas, na maioria das vezes, bastante conhecidas. O poeta não é apenas aquele que vê melhor do que os outros, como acreditava Goethe, pois deve ser também aquele que melhor estabelece relações entre coisas não só díspares entre si, já que são mesmo diferentes, mas também entre as que são semelhantes entre si e que, ao olhar comum, parecem não apresentar mais nada que pudesse ser relacionado entre elas - aí se instaura o trabalho do poeta, tirar o homem da acomodação a que ele se acostuma tão facilmente, propor-lhe novas possibilidades, desafiá-lo a olhar de novo para uma coisa conhecida e ver, ser capaz de ver, o novo e o inusitado. É nisso que acredito, nesse trabalho do poeta de forçar o homem (leitores comuns ou especializados, não importa) a ver as coisas corriqueiras e banais (mas também as diferentes e incomuns) como coisas sempre extraordinárias e assombrosas. Acho que parte deste trabalho do poeta é ser sempre desconcertante, de obrigar o homem a ver as coisas de forma desconcertante, de atrapalhar, de bagunçar com a forma sempre muito garantida que o homem tem das coisas ao seu redor, e obrigá-lo a ver o mundo como se de cabeça para baixo, invertido, subvertido e alterado.

A contista e romancista norte-americana Flannery O'Connor uma vez escreveu que "o escritor [...] vê sua obrigação relacionada à verdade do que pode acontecer na vida, e não ao leitor - não ao gosto do leitor, não à felicidade do leitor, nem mesmo à moral do leitor"6. Assim, o trabalho do poeta nunca é dar ao leitor o mundo tal como conhecido, mas como se visto pela primeira vez, inusitado, estranho e único, tal como dito por Fernando Pessoa/Alberto Caieiro, em "O Guardador de Rebanhos", sabendo ter "o pasmo essencial/ que tem uma criança se, ao nascer,/ reparasse que nascera deveras...", concluindo: "Sinto-me nascido a cada momento/ para a eterna novidade do Mundo..." Se não for assim, acredito, concordando com as ideias de Alberto Caieiro e de Flannery O'Connor, nenhuma criação poética faz sentido. Sem sentido, poesia alguma estará em crise - e por qual razão estaria? -, por isso jamais poderá enfrentar crise alguma, menos ainda superá-la.

Uma vez, entrevistado pela professora Solange Fiúza Yokozawa, fui por ela indagado se concordava com ideia de João Cabral de Melo Neto, no poema "Dúvidas apócrifas de Marianne Moore", de "que toda 
escrita é também uma autoescrita". Minha resposta foi, em primeiro lugar, que gostava muito de uma frase em que a poeta norte-americana diz ser poesia só substantivos e verbos (poetry is all nouns and verbs ${ }^{8}$ ). Evidentemente, ninguém deixa de usar adjetivos e advérbios, mas é um bom caminho andado rumo à impessoalização da poesia se o poeta os evita tanto quanto for possível, ao menos aqueles que não têm outro propósito senão o de desvendar, revelar ou expor uma relação e/ ou reação emocional do poeta. Advérbios e adjetivos que expressam qualquer coisa além e fora do meramente pessoal não me preocupam; se são descritivos e distanciam, uso-os bastante. Mas o que Cabral faz no poema "Dúvidas apócrifas de Marianne Moore" é também expor uma hesitação, quando indaga se no falar de coisas não haveria "um falar de mim". Aí reside o paradoxo que todo poeta tem de enfrentar, não? Pois falamos de nós mesmos até quando buscamos o maior nível de impessoalização possível. O poeta se fala, e sempre na crença ingênua de que sabe o que fala e de onde fala, de um lugar que acredita seu. Se isso existe ou é possível, já que são sempre duas as disposições: o poeta escreve e, ao mesmo tempo, se inscreve - escreve na folha em branco da página segundo uma tradição milenar que lhe é anterior; se inscreve através da repetição que instaura sua diferença. Ao escrever, todo escritor se faz paciente de um ato antecedente (o tecido etimológico da tradição cultural literária) e sujeito de um ato inaugural, o de ele se inscrever como 'escrevente'. A página em branco a ser preenchida é sempre o lugar, por isso, de possibilidades.

Acredito que um poeta não é sua escrita, mesmo que só possa aparecer através dela. O poema, na verdade, por mais confessional que seja, ou mais pessoal, nunca contém o que o poeta é, mas suas máscaras, suas omissões, seus deslocamentos, suas diferenças e sua fé derrogada, sempre uma fala mal enunciada. Daí todo poema ser não um fim, mas um processo, o tecido das relações significantes a que o mesmo Cabral se referiu em seu magistral "Tecendo a manhã": 'desde uma teia tênue' que 'se vai tecendo [...] e se encorpando em tela, entre todos, se erguendo tenda, onde entrem todos'. Não foi por isso que Jacques Derrida afirmou que não existe o "fora do texto"? 
Assim, Cabral está certo ao dizer, em "Dúvidas apócrifas de Marianne Moore", que ao falar de coisas o poeta fala de si mesmo, pois por mais que o poeta tente ser impessoal e esgarçar suas experiências, despersonalizando-as, indeterminando-as, não tem como escapar da tradição que o forma e informa, assim como da escrita que o inaugura: o poeta está no poema ao mesmo tempo em que se torna o poema que escreve, já que inexiste fora dele. Reconheço a impossibilidade da objetividade pura, mas reconheço também minha/nossa necessidade de buscá-la, evitando ao máximo a pura subjetividade.

Neste momento alguém poderia querer me indagar o que penso ser poesia. Cautelosamente diria que não sei, nem quero definir poesia, mesmo se algumas vezes certas definições de poesia nos surpreendam. Por exemplo, quem pensaria que o romantismo inglês pudesse começar com uma declaração como esta, de Samuel Taylor Coleridge: "Prosa: palavras na sua melhor ordem; poesia: as melhores palavras na melhor ordem"9? Isso implica em entender que poesia é sempre a melhor palavra no melhor lugar, e que isso não é só uma questão de escolha de uma palavra, mas da escolha, ao mesmo tempo, do melhor lugar para se colocá-la. Daí a ideia de que poesia é, antes de tudo, uma forma realizada da melhor maneira possível. Mas isso não ajuda muito ou não soluciona todos os nossos problemas ou crises.

Para mim - e não estou definindo nada -, poesia é um fazer de que resulta num objeto específico, com propósito e fins específicos. Poesia, sendo um ato de criação, é uma descoberta, com e através da linguagem, não só de novas formas de olharmos o mundo, mas de enfrentá-lo também, e tentarmos modificá-lo ou ao menos interferir, ao falarmos/escrevermos sobre esse mesmo mundo. Acima de tudo, poesia é uma forma de criação através da linguagem, pois a elaboração de um poema inclui, por ser a escolha da melhor palavra para o melhor lugar, de coerência linguística, riqueza ou até pobreza vocabular, efeitos sonoros, inclusão de ritmo, exploração de todas as possibilidades que a linguagem pode nos oferecer com e além da mera necessidade de comunicarmos alguma ideia ou qualquer coisa. Poesia comunica, é claro, mas comunica bem mais do que a mera mensagem, comunica sobretudo a forma através da qual foi criada, os jogos e efeitos sonoros, seus ritmos e suas violações das regras gramaticais e até mesmo sua 
obediência a elas. Em poesia não interessa apenas o que se diz; interessa, acima disso, a forma como se diz. Se ela é uma criação, é também uma descoberta de relações novas, quer no campo da aparência visual que tem, se escrita, mas também nas sonoridades e ritmos que estimula, ao apresentar infinitas variedades e combinações, se só oral - e tudo isso combinado ou interligado em sua elaboração ou criação. Essa é a forma através da qual a poesia é possível em tempos de qualquer crise.

Numa afirmação do poeta galês (do País de Gales), naturalizado norte-americano, W. H. Auden, encontramos a ideia de que "um poema é um artefato verbal que deve ser tão hábil e solidamente construído como uma mesa ou uma motocicleta" ${ }^{\prime 10}$. Isso combina bem com o que afirmei até aqui, que o fazer/criar poético não difere do fazer/criar industrial: difere quanto ao material utilizado, o objeto a ser criado ou produzido e os fins utilitários do objeto criado/produzido/fabricado. Por isso devo também dizer que não acredito em poesia de 'inspiração', se isso significa poesia espontânea, sem cuidadosa elaboração formal, poesia escrita depois de bebedeiras, de amores conquistados ou fracassados, de sentimentos exacerbados por consumo etílico, de qualquer coisa que não seja exatamente a escolha da melhor palavra no melhor lugar.

Poesia, para mim, é um artefato por ser um artifício, uma criação humana para fins humanos, sejam quais forem, mas uma criação consciente e muito bem elaborada da linguagem. Volto atrás, novamente, para recuperar a ideia de Horácio, em sua Carta aos Pisões ou Arte Poética, para lembrar que para fazer poesia dependemos do ingenium e da ars, quer dizer, do "engenho" e da "arte", tal como essas palavras foram traduzidas por Camões, ao fim da segunda estrofe de $O s$ Lusíadas: "Cantando espalharei por toda parte,/ Se a tanto me ajudar o engenho e arte", pois o grande poeta português sabia que não basta querer fazer, é preciso saber como fazer: não basta a inclinação natural do homem para escrever poesia (ingenium), é preciso técnica para o homem escrever poesia (ars). É preciso treinamento, adequação e instrumentalização, aprendizagem. Insisto que não acredito em poesia espontânea, fruto do acaso ou da sorte ou de cópia de procedimentos alheios. Retomo e repito João Cabral de Melo Neto, em "Psicologia da Composição", que poesia não é "a forma encontrada", não é "a forma

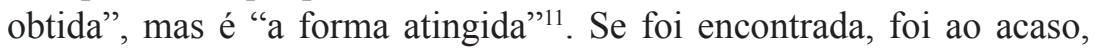


pode ser mera cópia de feito alheio; se foi obtida, foi em "lance santo ou raro", nunca será repetido; se é atingida, é por coerência de propósitos e elaboração consciente - esta é a forma melhor, por ser o resultado de um trabalho individual e paciente, fruto de dedicação e persistência, jamais cópia ou repetição de processos alheios.

Não descarto a inspiração, se entendida como esse instante em que a ideia vem, o problema aparece, e aí se segue a elaboração, às vezes mais rápida, às vezes mais lenta do poema; aliás, de qualquer texto. Acredito, com Aristóteles, que a poesia tem duas causas e ambas são naturais: aprendemos através da imitação e temos prazer com e através dela. Paul Valéry não disse algo mais ou menos assim, que os deuses dão uns dez por cento (se tanto), o poeta é obrigado a contribuir com o restante? Acredito muito nisso. Não acredito em poesia fruto de escrita espontânea, aos jorros, que brota de repente e sai sob falta de controle e se crê a exteriorização de emoções e paixões violentas ou até mínimas. Para mim isso não é poesia, mas a negação dela.

Neste ponto, poder-se ia objetar: "Mas ele não disse, até agora, sobre qual poesia é possível em tempo de crise!" E isso torna-se um problema, pois penso que não falei de outra coisa a não ser exatamente disso. Para confirmar, quero apresentar um outro poema, do norte-americano Donald Caswell ${ }^{12}$, nascido em 1948. A tradução também é minha:

\section{Por Que Sou um Poeta}

Não sou poeta. Nem sou um carpinteiro. Algumas vezes, penso que preferiria ser um carpinteiro, mas não sou. Por exemplo, o Gene, meu amigo carpinteiro, está construindo uma casa. Eu passo por lá. Ele me dá um martelo e diz, 'Comece a martelar.' Eu martelo, nós martelamos. Olho pra cima. 'Onde está o telhado?' Não cheguei tão longe, ainda,' diz ele. Eu me vou e os dias se vão, e eu passo por lá outra vez. O telhado está no lugar e eu me vou e os dias se vão, e eu começo um poema. Estou pensando em estrelas e escrevo um poema sobre estrelas. Pego uma máquina de escrever e começo a martelar. Logo, há páginas, acres de palavras sobre estrelas e o café acaba e, então, vou para um restaurante. Compro uma cerveja e uma mulher perto de mim me diz como ela foi violentada pelo 
seu padrasto, quando tinha apenas doze anos, e, então, como que ela fugiu com um ex-presidiário, que foi pego de novo por causa de cocaína e deixou-a grávida, e então como ela se casou com um recruta e se mudou para a Alemanha, onde a criança morreu de doença nos rins, e então como ela voltou pra casa pra morar com a mãe dela. E eu bebo um monte de cerveja. Depois, vou lá pra fora e me deito num lote vago, olhando para as estrelas e pensando quantas delas existiam e que poema maravilhoso elas dariam. E caio no sono, com uma cerveja na mão. De manhã, a cerveja, as estrelas e minha carteira se foram, e então vou ver o Gene e a casa está pronta. Uma família está vivendo lá e eles me mostram o cachorro deles. Há flores desabrochando, repolho sendo cozido na cozinha. Então vou pra casa e escrevo um outro poema. E um dia o Gene aparece. Olha para o poema e agora são doze poemas, todos certinhos, empilhados e prontos para serem lidos e ele pergunta 'Onde estão as estrelas?' E eu digo, 'Não cheguei tão longe ainda.'

Talvez seja esse o destino de todo poeta, nunca chegar tão longe, condenados que somos a estar sempre a um passo aquém e outro a ser dado além e a mais. Acima de tudo, somos sempre forçados a ter de explicar o que fazemos e como fazemos tudo o que fazemos. É por isso que quero apresentar mais um exemplo e, através dele, muitos talvez leiam pela primeira vez uma poeta do Zimbábue, Freedom Nyamubaya $^{13}$, poeta e guerrilheira na luta pela independência de seu país e oficial comandante de seu exército. Ela escreveu um poema intitulado "Poesia", que apresento aqui, em tradução também minha:

\section{PoEsIA}

Alguém disse:
Você não é poeta,
Pois se esqueceu de que
Poesia é uma arte e-
Arte é ritmo com sentido.
Agora, o que é ritmo,
Se posso perguntar?
Alguns dizem que são sílabas marchando, 
Outros, que são sons marchando,

Agora me digam como casar os dois.

Lutamos contra Shakespeare no campo de batalha.

Negros lutaram contra os boers com suas lanças.

Estas são sílabas marchando

E isto é arte para alguns,

Mas como posso casar os dois?

Que tal um ritmo diferente?

Pessoas morrem nos guetos,

De ataques da polícia e tiros do exército,

Trabalhadores sufocam dentro de minas de carvão,

Cavando o carvão que não têm com que comprar,

Para cozinhar diariamente e se alimentarem.

Coisas poéticas estas.

Então, concordemos em discordar -

A arte serve.

Eis um poema que relembra a eterna crise em que se encontra a poesia e de como ela é, além de estética, também política, mas não é minha intenção explicar este aspecto do poema, nem suas razões estéticas. O poema de Nyamubaya é por demais explícito, não demandando explicações.

Quero apenas concluir este ensaio, mas não sem antes dar um outro exemplo, agora retirado do final de um ensaio da romancista Lynn Freed ${ }^{14}$, nascida em Durban, na África do Sul, mas professora nos Estados Unidos. O ensaio é intitulado "Não Causando Dano: Algumas Ideias sobre Leitura e Escrita numa Era de Ressentimento" - subentendese, é claro, crise. No final do ensaio, ela reconta a experiência de uma professora de escrita criativa numa universidade da Califórnia:

Alguns anos atrás, uma poeta que eu conhecia contou-me a história de um curso que ela ministrara na Southern California [University]. Dele participava uma senhora que sobrevivera a Auschwitz. Ela escrevia sobre isso, mas os poemas eram um fracasso. Eram simples litanias de horror, sofrimento, miséria, tudo abstrato, soando sempre 
como se tivessem sido escritos muitas vezes antes. Num poema, ela escreveu sobre crianças sendo levadas para a morte. E aí todos os alunos participantes do curso reagiram com frases de horror e revolta. Mas nada no poema parecia mais real do que a ideia em si mesma - nenhuma imagem, nenhuma frase, nada que fizesse o sangue gelar.

"Diga-me", disse a professora, "o que você viu quando aquelas crianças passaram por você, sendo levadas? Diga-me o que você ouviu."

A sobrevivente balançou negativamente a cabeça. "Não podíamos ver porque havia um muro", disse ela. "E não podíamos ouvir por causa dos gansos".

"Gansos?" disse a professora.

“Ah, sim", disse a sobrevivente. "Os alemães mantinham um rebanho de gansos. Eles apanhavam para que grasnassem e não pudéssemos ouvir as crianças chorando enquanto eram levadas para as câmaras de gás."

Assim, lá estava o poema. E os alunos estavam, por fim, em lágrimas.

Desta forma Lynn Freed conclui suas "ideias sobre leitura e escrita numa era de ressentimento". Creio não desrespeitá-la ao dizer que em tempo de qualquer crise, a única poesia possível é a que tenta ver acima e além de todos os muros; que tenta ouvir todo choro abafado pelo barulho do grasnar de quaisquer gansos.

Quando conseguirmos isso, se até isso pudermos chegar, poetas e público serão enfim leitores de uma mesma realidade.

\section{PoETRY AND CRISIS: HIGH WALLS AND HONK OF GEESE}

\section{Abstract}

This essay tries to show, through the reading of some poems e one prose fragment by different authors (Nicanor Parra, Eve Merriam, Donald Caswell, Freedom Nyamubaya and Lynn Freed), how the crises through which poetry is transformed are constituted as well as how poets of different nationalities and purposes accept the challenge and try to overcome them.

Keywords: Poetry and poetic crises, Poetic challenges, Poetic changes. 


\section{RESUMEN}

Este ensayo pretende mostrar, a través de la lectura de algunos poemas y un fragmento en prosa de diversos autores, (Nicanor Parra, Eve Merriam, Donald Caswell, Freedom Nyamubaya y Lynn Freed), cómo se constituyen las crisis a través delas que la poesía se transforma y, de qué forma poetas de diferentes nacionalidades y propósitos aceptan el reto y tratan de superarlo.

Palabras clave: Poesía y crisis poética, Desafíos poéticos, Transformaciones poéticas.

\section{Notas}

1 Este trabalho só se tornou possível graças a uma bolsa de apoio à participação em eventos científicos e tecnológicos concedida pela FAPEG - Fundação de Amparo à Pesquisa do Estado de Goiás.

2 Nicanor [Segundo] Parra [Sandoval] (1914-), poeta, matemático e físico chileno, irmão da compositora e cantora Violeta Parra, publicou inúmeros livros: Cancionero sin nombre (1937), Poemas y antipoemas (1954), Manifiesto (1963), Poesía política (1983), Obras completas I \& algo + (2006), Obras Completas II \& algo + (2011). Nas duas partes citadas do poema pode-se ler, em tradução minha: "V// Jovens//Escrevam o que quiserem/ No estilo que lhes pareça melhor/ Muito sangue já correu sob pontes/ para se seguir acreditando - creio eu/ Que só se pode seguir um caminho:/ Em poesia se permite tudo"; "VIII//O dever do poeta/ consiste em superar a página em branco/ Duvido que isso seja possível". Disponível em: $<$ https://www.nicanorparra.uchile.cl/antologia/otros/cartaspoeta.html>. Acesso em: 25 abr. 2016.

Este poema pode ser encontrado, em versão muitíssimo adulterada, como se as partes V e XIII do poema fossem uma só, com um título inventado pelo tradutor (Young Poets) no sítio Poems on Poems <http://www.tnellen.com/ cybereng/poetry/>, na página <http://www.tnellen.com/cybereng/poetry/ youngpoets.ht ml>, em sua tradução para o inglês por Miller Williams. 
3 Eve Merriam (1916-1992) foi poeta, escritora de livros infantis e dramaturga. Alguns livros de sua poesia para adultos: Family Circle (1946), Tomorrow Morning (1953), The Double Bed from the Feminine Side (1958), The Inner City Mother Goose (1969), A Husband's Notes about Her (1976), Embracing the Dark: New Poems (1995).

4 Este poema, assim como todos os outros traduzidos, citados e transcritos neste ensaio já foram por mim publicados em outro ensaio, "Poesia: Modos de Ver", na revista do Programa de Pós-Graduação em Letras e Linguística da Faculdade de Letras da Universidade Federal de Goiás: Signótica Especial, Estudos Literários, n. 1, p. 303-317, 2006.

5 Poética 1451 b 27 (IX - 54). Trad. Eudoro de Souza. São Paulo: Abril Cultural, 1973, p. 451.

6 Mystery and Manners: Occasional Prose. New York: Farrar, Straus, and Giroux, 1963. Disponível em: $<$ https://w ww.catholicculture.org/culture/library/view. cfm?recnum=9118>. Acesso em: 28 abr. 2016. O mesmo fragmento pode ser encontrado em SEEL, Cynthia L. Ritual Performance in the Fiction of Flannery O'Connor. Rochester, NY: Camden House, 2001. p. 46.

7 Poemas completos de Alberto Caieiro. In: PESSOA, Fernando. Obra poética. Rio de Janeiro: Aguilar, 1960. p. 139.

8 New York Times, March 22, 1962, p. 31.

9 No original, em Table Talk: "I wish our clever young poets would remember my homely definitions of prose and poetry; that is, prose, - words in their best order; poetry, - the best words in their best order." Disponível em: John Bartlett (1820-1905). Familiar Quotations, 10. ed. 1919. <http://www. bartleby.com/100/34 0.77.html>. Acesso em: 18 abr. 2016.

10 ARANA, R. Victoria. W.H. Auden's Poetry: Mythos, Theory, and Practice. Amherst-NY: Cambria Press, 2009. p. 156. Auden, no trecho citado, está discutindo a obra do poeta russo Andrei Voznesensky.

11 Ver: Obra completa. Rio de Janeiro: Aguilar, 1994, p. 95-96.

12 Donald [Eugene] Caswell (1948-) é um poeta, jornalista e professor norteamericano. Algumas obras: Watching the Sun Go Down (1977), A Nail in My Boot (1980), The Boy That Was Made out of Wood (1991), Fake Picassos (1994), Three-Legged Dog (1999). 
13 Freedom Nyamubaya (1960-2015) foi poeta, soldado, oficial do Exército Nacional de Libertação do Zimbábue em Moçambique, ativista do desenvolvimento rural em seu país. Publicou: On the Road Again (1985), Ndangariro (1987), Dusk of Dawn (1995).

14 Lynn Freed (1945-), sul-africana radicada nos Estados Unidos, é romancista, contista e ensaísta. Algumas obras: Friends of the Family (pela primeira vez publicado como Heart Change; 1982), Home Ground (1986), The Bungalow (1993), The Mirror (1997), House of Women (2003), The Curse of the Appropriate Man(2004), Reading, Writing \& Leaving Home: Life on the Page (2009). Disponível em: <http://w ww.lynnfreed.com> ou $<\mathrm{http}: / /$ www.narrativemagazine.com/issues/winter2016/nonfiction/doing-no-harm -some-thoughts-reading-and-writing-age-umbrage-lynn-freed $>$. Acesso em: 12 abr. 2016.

\section{REFERÊNCIAS}

ARISTÓTELES. Poética. Tradução Eudoro de Souza. São Paulo: Abril Cultural, 1973.

ARANA, R. V. W.H. Auden's Poetry: Mythos, Theory, and Practice. AmherstNY: Cambria Press, 2009.

COLERIDGE, S. T. Table Talk. In: BARTLETT, John. Familiar Playstation. 10. ed. 1919. Disponível em: <http://www.bartleby.com/100/34 0.77.html>.

GODOY, Heleno. "Poesia: Modos de Ver". Signótica Especial, Estudos Literários, n. 1, p. 303-317, 2006.

MELO NETO, J. C. Obra completa. Rio de Janeiro: Aguilar, 1994.

O'CONNOR, F. Mystery and Manners: Occasional Prose. New York: Farrar, Straus, and Giroux, 1963.

PESSOA, F. Obra poética. Rio de Janeiro: Aguilar, 1960, p. 139.

POEMS ON POEMS. Disponível em: <http://www.tnellen.com/cybereng/ poetry/s.

SEEL, C. L. Ritual Performance in the Fiction of Flannery O'Connor. Rochester, NY: Camden House, 2001.

Submetido em 10 de julho de 2016.

Aceito em 30 de setembro de 2016.

Publicado em 12 junho de 2017. 